\title{
About the mechanism of the hail formation
}

\author{
Ismailov Sokhrab Akhmedovic \\ Doctor of Chemical Sciences, Institute of Petrochemical Processes, Academy of Sciences of Azerbaijan, Baku
}

Email address:

sokhrab@yahoo.com

\section{To cite this article:}

Ismailov Sokhrab Akhmedovic. About the Mechanism of the Hail Formation. Science Discovery. Vol. 2, No. 2, 2014, pp. 27-33. doi: $10.11648 /$ j.sd.20140202.11

\begin{abstract}
The new hypothesis about the building mechanism of hail showers is made under atmosphere conditions. It is suggested, contrary to other famous theories that hail showers building is stipulated by the generation of high temperature in lightning strike in atmosphere. Quick water evaporation along and around the discharge channel leads to its rough freezing with the advent of hail showers of different size. The transition of zero- degree isotherm is not necessary for the building of hail showers; they are formed in the lower atmosphere. Storm is accompanied by hail showers. Hailstorm is observed only in case of severe thunderstorm.
\end{abstract}

Keywords: Hailstone, Zero Temperature, Evaporation, Cold, Lightning, Storm

People are often confronted with terrible natural phenomena of nature and constantly fight against them. Natural disasters and the consequences of catastrophic natural events (earthquakes, landslides, lightning, tsunamis, floods, volcanic eruptions, tornadoes, hurricanes, hail) attracted the attention of scientists from all over the world. It is no accident that when UNESCO had established a Special Commission on account of natural disasters-UNDRO (United Nations Disaster Relief Organization-disaster response by the United Nations). Knowing the objective world, and acting in accordance with it, the man subdues nature forces them to serve its purposes and turns from a slave nature in the Lord of nature and ceases to be powerless before nature, becomes free. One of those scourges is hail.

The fall of the hail, first of all, destroys cultural combines of plants, kills livestock, as well as the man himself. The fact of the matter is that a sudden and large influx of offensive hail eliminates protection against it. Sometimes in a matter of minutes the Earth's surface is covered with a layer with a thickness of 5-7 cm. In the area of Kislovodsk in the 1965 year was hail, covering the ground layer in $75 \mathrm{~cm}$. Normally hail covers the 10-100 km distance. Let us remember some terrible events of the past.

In 1593, in one of the provinces of France due to the raging winds and lightning knocked out the sparkling hail with a huge weight of $18-20$ pound! This has caused great damage to crops and destroyed many churches, castles, houses and other structures. The victims of this terrible event began and the people themselves. (Here it is necessary to consider that in those days the pound as a unit of weight has several meanings). It was a terrible natural disaster, one of the most disastrous hailstones that hit France. In the eastern part of the State of Colorado (United States) annually about six hailstones, each of them brings great losses. Hail most frequently occur in the North Caucasus, Azerbaijan, Georgia, Armenia, in the mountains of Central Asia. With 9 on June 10,1939 , in the city of Nalchik dropped hail the size of a chicken egg, accompanied by heavy rain. As a result, was destroyed over 60 thousand hectares of wheat and about 4 thousand hectares of other crops; 2 were killed thousands of sheep.

When it comes to the hailstone, first of all, pay attention to the size of it. Hailstones, as usual, are different in size. Meteorologists and other researchers draw attention to themselves the largest. Curious to know about absolutely fantastic hailstone. In India and China it was found falling from heaven ice blocks weighing 2-3 kg. Even say that in the year 1961 in North India heavy hailstone killed the elephant. In 14.04.1984 year in the small town of Gopalganj district of Bangladesh dropped hailstones weighing $1 \mathrm{~kg}$, resulting in the deaths of 92 people and several dozen elephants. Even the hail entered into the Guinness Book of records. In 1988, the 250 people in Bangladesh were victims of hail. And in 1939 , hailstone was found with a weight of $3.5 \mathrm{~kg}$. More recently (20.05.2014) in the city of Sao Paulo of Brazil has such a large dimension of hailstone, a bunch of which were 
extracted from the streets of heavy equipment.

All these data suggest that the damage to human life with hail is important, other than the extraordinary natural phenomenon. Based on this, a comprehensive study and finding reasons for the formation of its using modern physic-chemical methods of research, as well as the fight against this terrible phenomenon are current challenges before mankind around the world.

\section{What is the Mechanism of Hail Formation}

In advance, I note that is still no proper and positive response to this question. Despite the creation of the first hypothesis about this back in the first half of the 17th century, Descartes, however, scientific theory hail processes and practices impact on Physics and meteorologists have developed only in the middle of the last century. It should be noted that even in the middle ages and in the first half of the 19th century there have been several assumptions of different researchers, such as, Bussengo, Swedes, Klossovskij, Volta, Rayee, Ferrell, Gan, Faraday, Zonke, Reynold, etc. Unfortunately, their theory did not receive their confirmation. It should be noted that and modern views on this matter are not scientific substantiated, and there is still not comprehensive picture about the mechanism of formation of the hail. The presence of numerous experimental data and a set of literary materials, dedicated to this topic were given the opportunity to assume the next formation mechanism of hail, which was recognized by the World Meteorological Organization and continues to operate so far (to avoid controversy, we literally give these arguments) $[1,6,21]$ :

"Rising from the Earth's surface on a hot summer day, the warm air cools with height, and the moisture is condensed, formed a cloud. Cooled liquid droplets in the clouds are found even when the temperature is $-40{ }^{\circ} \mathrm{C}$ (at a height of about $8-10 \mathrm{~km})$. But these drops are very unstable. Raised from the Earth's surface the smallest particles of sand, salt, combustion products and even bacteria with super cooled drops disturb the fragile balance. Cooled liquid drops that came into contact with solid particles, turn into an ice embryo of hailstones.

Small hailstones are in the top half of almost every cumulonimbus clouds rain, but most often such hailstones when approaching the Earth's surface are melting. So, if the speed of the upward flow in a cumulonimbus cloud rain reaches $40 \mathrm{~km} / \mathrm{h}$, they cannot keep the hailstones formed, therefore, passing through a warm layer of air at a height of 2.4 to $3.6 \mathrm{~km}$, they fall out of the clouds in the form of small soft hail or rain at all. Otherwise, the updrafts lift the small hailstones up to layers of air with temperature from- $10^{\circ} \mathrm{c}$ to- $40^{\circ} \mathrm{c}$ (height between 3 and 9 miles), a diameter of hailstones begins to grow, reaching sometimes several centimeters. It should be noted that in exceptional cases the speed of ascending and descending cloud flows can reach
$300 \mathrm{~km} / \mathrm{h}$ ! And the higher the speed the upward flow in a rain cloud, cumulonimbus, the larger the hail.

For the formation of hailstones the size of a golf ball more than 10 billion needed super cooled water drops, and hailstone cloud must remain at least 5-10 minutes to reach such a large size. It should be noted that a single drop of rain is about a million such small super cooled droplets. Hailstones with a diameter of more than $5 \mathrm{~cm}$ in cumulonimbus clouds, which are very powerful rising air currents. It is thunderstorms produce tornadoes, heavy downpours and gusts.

Hail usually falls when severe thunderstorms in the warm season, when the temperature on the surface of the Earth above $20^{\circ} \mathrm{C}$ ".

It must be stressed that even in the middle of the last century, or rather, in 1962; Ludlam also proposed a similar theory [16] provides the education prerequisite hailstones. He also discussed the formation of hailstones in the super cooled part of the cloud of small water droplets and ice crystals by coagulation. Last operation must be strong lifting and lowering of the hailstones several kilometers, passing a null isotherm. On the type and size of hail, and modern scholars say that the hailstone during his life several times to get up and down the strong convection currents. As a result of the collision with the super cooled drops of hailstones increase their size. The World Meteorological Organization in 1956 gave a definition of what a hail: "Hail-precipitation in the form of spherical particles or pieces of ice (hailstones) with a diameter ranging from 5 to $50 \mathrm{~mm}$, sometimes more, falling separately or in the form of incorrect complexes. Hailstones consist only of transparent ice or of a number of layers with a minimum thickness of $1 \mathrm{~mm}$, alternating with translucent layers. Hail is observed usually in strong thunderstorms".

Almost all of the former and contemporary sources on the subject indicate that the hail is formed by a powerful concentrate the cloud at strong upward air flows. This is true Unfortunately, most forgotten about lightning and thunderstorms. And the subsequent interpretation of the formation of hailstones, in our view, It is not logical and pointless.

Professor Klossovskij carefully reviewed the appearances of hailstones and discovered that they also have a number of spherical form other geometric forms of existence [8]. These data indicate the formation of hailstones in the troposphere on a mechanism. After reading all of these theoretical perspectives, caught our attention several intriguing questions:

1. Composition of the clouds, found at the top of the troposphere, where temperature is approximately $-40 \mathrm{oC}$ operating system already contains a mixture of super cooled of water droplets, ice crystals and sand particles, salts, bacteria. Why not disturbed the fragile power balance?

2 . With the recognized modern general theory $[1,6,21]$, hailstone could emerge and no lightning or thunder storm. For the formation of hailstones with a larger size, small ice must climb a few kilometers up (at least 3-5 km), and fall 
down, passing a null isotherm. While this should be repeated until it was formed in a sufficiently large amount of hail. Still the same, the greater the upward flow velocity in the cloud should get, the bigger the hailstone (from $1 \mathrm{~kg}$ to several $\mathrm{kg}$ ) and for the consolidation of it should remain in the air for 5-10 minutes. Interesting!

3 . In general, it is difficult to imagine that in the upper atmosphere will focus as huge ice blocks weighing 2-3 kg? It turns out that the hailstones were still large in cumulonimbus cloud rain than seen on earth because of it melted when falling through the warm layer of the troposphere.

4. Because meteorologists often confirm: ". ... hail usually falls when severe thunderstorms during summer, when the temperature at the Earth's surface is below $20 \mathrm{oC}$ ", however, does not indicate the cause of the phenomenon. Of course, the question is: what is the effect of a lightning storm? Hail almost always falls to the shower or at the same time with him and never after. He falls for the most part in the summer and during the day. Hail at night - a very rare phenomenon. The average duration of hail - from 5 to 20 minutes. Hail as usual, going to the place where there is a strong bolt of lightning, and is always associated with a thunderstorm. Without lightning hail does not happen! Hence, the reason for the formation of hail, we need to look for in it. The main drawback of all existing mechanisms for the formation of hail, in our opinion, is the lack of recognition of the dominant role of the lightning discharge.

Studies of the distribution of hail and thunderstorms in Russia, produced A.V. Klossowski [8] confirm the existence of a particularly close link between these two phenomena: hail with thunderstorms usually happens in the south-eastern part of the cyclone; he often where most thunderstorms. North of Russia is poor cases of hail, in other words, hail, the cause of which is explained by the lack of strong lightning. And what role is played by lightning?

No explanation several attempts to find a connection between the hail and the storm still were in the middle of the 18th century. [9]. Guyton de Morvo Chemist, rejecting all the existing ideas, offered his theory: electrified the cloud better conduct electricity [20]. But Nolle [23] put forward the idea that water evaporates faster when she electrified and reasoned that it must amplify the chill and the fantasized that couples can become the best conductor of heat, if you put electricity on them. Guyton criticized Jean Andre Monsey and wrote, [22]: it is correct that electricity increases evaporation, but electrified drops must mutually repel and not merge into large hailstones. The electrical theory of hail was offered another famous physicist Alexander Volta [25]. In his view, the electricity was used as the root causes of the cold, and to explain why hailstones remain suspended for so long, that manage to grow. Cold is the result of very rapid evaporation of clouds, which contributed to the strong sunlight, rarefied dry air, lightness of volatilization of bubbles, which are made of clouds, and the estimated effect of electricity, which helps evaporation. But as the hailstones are kept in the air for sufficient time? For this reason Volta to look only for electricity. Well, how?
Anyway, to the 20 years of the 19th century there was a general belief that the combination of hail and lightning simply means that both of these effects occur when the same weather conditions. This was clearly expressed in 1814; the view of von Bush [17] and in 1830 it was strongly asserted Olmsted of Denison Ielâ [24]. Since then, the theory of hailstones was mechanical and based more or less steadily on perceptions of ascending air flows. On the theory of Ferrell [18], each hailstone may repeatedly fall and rise. The number of layers in the hailstone, which are sometimes up to 13, Ferrell' judged the speed of hailstone. Circulation occurs until the hailstones do not become very large. By his calculation, rising current speeds of $20 \mathrm{~m} / \mathrm{s}$ is unable to hail in $1 \mathrm{~cm}$ in diameter, and the speed for tornadoes is quite moderate. There are a number of relatively new scientific research $[11,13,14]$, devoted to the issues of formation of hail. In particular, argue that the history of the hail is reflected in its structure: large hailstone, cut in half, is similar to the root: it is composed of multiple layers of ice. Sometimes hailstones like pie, where alternate ice and snow. And this is his explanation for such layers, you can calculate the number of times a piece of ice was on a journey from the rain clouds in the supercool layers of the atmosphere. It is hard to believe: Grad with a weight 1-2 kg could jump back up to distances of 2-3 km? The layering of ice (hailstones) can appear for a variety of reasons. For example, the difference between the ambient pressures will cause such a phenomenon. And, in General, and here is the snow? This is snow?

In a recent site

http://tornado2.webnode.ru/obrazovanie-grada/ Yegor Chemezov puts forward his idea and tries to explain the formation of hail and his ability to stay for a few minutes in the air with the advent of the "black hole" in the cloud. In his view: "The hailstone has a negative charge. The greater the negative charge of the object, the less the concentration of ether (physical vacuum) in the site!? And the less the concentration of air in the material object, the more anti-gravity he possesses. On Chemezov, the black hole is a good trap for hailstones. Once, lightning, is a negative charge, and start falling hailstones.

Analysis of the literature shows that in this area of science has a lot of flaws and often speculation. On completion of the all-Union Conference in Minsk in 13.09.1989, devoted to the theme: "Synthesis and investigation of prostaglandins," we are in the middle of the night with the staff of the Institute were returning by air from Minsk in Leningrad. A flight attendant reported that our plane flies at an altitude of $9 \mathrm{~km}$. We watched the monstrous spectacle. Below us from us in a distance of about $7-8 \mathrm{~km}$ (just above the surface of the Earth) as though was a terrible war. These were powerful storm level. While the above our cloudy and shining star. And when we were over Leningrad, reported to us that an hour ago in the city went to hail with rain. With this episode I want to emphasize, that the strong lightning often sparkles closer to the ground. For the occurrence of hail and lightning did not necessarily raise the flow of 
cumulonimbus at the height of $8-10 \mathrm{~km}$. And there is no need to move the clouds above a zero isotherm. Huge ice blocks are formed in the warm layer of the troposphere. For such a process does not require freezing temperatures and high altitude. Everyone knows that without the thunderstorm and lightning no hail. Apparently, for electrostatic fields don't have collision and friction for small and large crystals of solid ice, as often write, although the phenomenon of friction hot and cold enough clouds in the liquid state (convection). For the formation of thundercloud requires plenty of moisture. When the same relative humidity, warm air contains more moisture than cold air. Therefore, Thunder and lightning, usually occur during the warm seasons-spring, summer, autumn. The mechanism of electrostatic field in the clouds also remains an open question. There is much speculation on the subject [9]. In one recent reported [5] that the rising moist air flows along with not charged cores are always present, positively and negatively charged nucleus. Any of them could be condensation. Found that the condensation of moisture in the air, the first begins to negatively charged nuclei, than neutral or positively charged nuclei [10.12]. For this reason, at the bottom of the clouds accumulate negative particles, and the top is positive. Therefore, inside the clouds created a huge electric field intensity which is $10^{6}-10^{9} \mathrm{~V}$ and the current $10^{5}-3 \cdot 10^{5} \mathrm{~A}$ such a strong difference of potentials, in the end, leads to a powerful electric discharge. Lightning can last $10^{-6}$ (one millionth) of a second. On time discharge lightning released an enormous thermal energy and temperature is $30000{ }^{\circ} \mathrm{K}$. This is about 5 times greater than the Sun's surface temperature. Of course, this huge energy area particle must exist in the form of plasma, which after recombination becomes neutral atoms or molecules.

\section{What can Cause this Terrible Heat}

Many know that when strong lightning discharge neutral molecular oxygen for air is easily converted into ozone, and is it felt peculiar smell:

$$
2 \mathrm{O}_{2}+\mathrm{O}_{2} \rightarrow 2 \mathrm{O}_{3} \uparrow
$$

In addition, it is established that in these harsh environments simultaneously reacts chemically inert nitrogen with oxygen to form mono-NO and nitrogen dioxide $\mathrm{NO}_{2}$ :

$$
\begin{aligned}
& \mathrm{N}_{2}+\mathrm{O}_{2} \rightarrow 2 \mathrm{NO}+\mathrm{O}_{2} \rightarrow 2 \mathrm{NO}_{2} \uparrow \\
& 3 \mathrm{NO}_{2}+\mathrm{H}_{2} \mathrm{O} \rightarrow 2 \mathrm{HNO}_{3} \downarrow+\mathrm{NO}
\end{aligned}
$$

Formed $\mathrm{NO}_{2}$ nitrogen dioxide in turn, react with water, becomes a nitric acid $\mathrm{HNO}_{3}$, which in the sediment falls to the ground.

Previously thought that containing in cumulonimbus clouds of table salt $(\mathrm{NaCl})$, carbonate $\left(\mathrm{Na}_{2} \mathrm{CO}_{3}\right)$ alkaline and alkaline earth metals $\left(\mathrm{CaCO}_{3}\right)$ react with nitric acid and eventually formed nitrates.

$$
\begin{gathered}
\mathrm{NaCl}+\mathrm{HNO}_{3}=\mathrm{NaNO}_{3}+\mathrm{HCl} \\
\mathrm{Na}_{2} \mathrm{CO}_{3}+2 \mathrm{HNO}_{3}=2 \mathrm{NaNO}_{3}+\mathrm{H}_{2} \mathrm{O}+\mathrm{CO}_{2} \\
\mathrm{CaCO}_{3}+2 \mathrm{HNO}_{3}=\mathrm{Ca}\left(\mathrm{NO}_{3}\right)_{2}+\mathrm{H}_{2} \mathrm{O}+\mathrm{CO}_{2}
\end{gathered}
$$

Nitrate when mixed with water leads to cold. Adhering to this, Gassendi fantasized that the upper layers of air are cool, not because they are far away from the source of heat reflecting from the Earth, and because of the "corpuscles" nitrogen (nitrate) out there that are very numerous. In winter it is the less and they generate only snow, but in summer more, so there may be hail [19]. Subsequently, this hypothesis has also been subject to criticism by his contemporaries.

\section{That Can Happen with Water under Such Harsh Conditions}

In the literature there is no information. Heating to a temperature $2500{ }^{\circ} \mathrm{C}$ [2] or through the water steady electric current at room temperature [7] it is decomposed into its component parts and thermal effect of reaction is shown by equation (7):

$$
\begin{array}{r}
2 \mathrm{H}_{2} \mathrm{O}(\text { liq }) \rightarrow 2 \mathrm{H}_{2} \uparrow(\mathrm{g})+\mathrm{O}_{2} \uparrow(\mathrm{g})-572 \mathrm{kC} \\
2 \mathrm{H}_{2} \uparrow(\mathrm{g})+\mathrm{O}_{2} \uparrow(\mathrm{g}) \rightarrow 2 \mathrm{H}_{2} \mathrm{O}(\text { liq })+572 \mathrm{kC}
\end{array}
$$

Reaction of decomposition of water (7) is an endothermic process, and to break covalent bonds energy must be imposed from the outside. However, in this case it comes from the system itself (in this case - polarized electrostatic water). This system reminds the adiabatic process, after which there is no gas heat exchange with the environment and such processes are very fast (lightning).

In short, when the adiabatic expansion of water (decomposition of water into hydrogen and oxygen) (7) is its internal energy and therefore starts to cool itself. Of course, when the lightning discharge balance evenly shifted rightward, and gases, hydrogen and oxygen - the influence of electric arc instantly with a bang ("explosive mixture") react to form water (8). This reaction is easy to hold in the laboratory. Despite a decline in volume of reactive components in this reaction, the result is a strong rumbling. The speed feedback based on Le Chatelier's principle affects favourably received by reaction (7) high pressure. The fact of the matter is that and direct reaction (7) should be strong with a roar, as liquid water modular condition instantly formed gases (most authors attribute this to intense heating and expansion within or around the channel of air created by a discharge of Lightning). It is possible that the sound of thunder, therefore, is not monotonous, that is, not to mention the sound of an explosive or weapon. First comes the decomposition of water (first thunder), followed by accession of hydrogen with oxygen (the second thunder). However, these processes are occurring so quickly, they discern not everyone. 


\section{As is Formed Hail}

When the lightning begins due to the tremendous amount of heat, the water in the channel of lightning or around his intensely evaporates as soon as stop flashing lightning, it starts to freeze. In the well-known law of Physics: a strong evaporation leads to cooling. It is noteworthy that the heat during discharge of lightning are not imposed from the outside, on the contrary, it derives from the system itself (in this case system: a polarized electrostatic water). The process of evaporation is the kinetic energy of the polarized water system. In this process, a strong and instant evaporation of water causes a sharp its solidification. The stronger the evaporation, the more intense is the process of solidification of water.

For such a process is not necessary that the ambient temperature was below zero. The lightning discharge generates a variety of different and the size of the hailstones. The hailstones depend on the power and intensity of lightning. The stronger and more intense lightning are, the larger the hailstone. Usually the hail stops as soon as quickly stops flashing lightning.

Similar processes operate in other areas of nature. Here are a few examples.

1. Refrigeration systems operate on the principle. That is, artificial cold (freezing temperatures) is formed in the evaporator in a boiling liquid refrigerant that is served up by the capillary tube. Due to the limited bandwidth of the capillary tube, the refrigerant enters the evaporator relatively slowly. Boiling temperature of the refrigerant generally makes about $-30{ }^{\circ} \mathrm{C}$. Getting into the warm evaporator, refrigerant instantly boils heavily cooling evaporator wall. Vapors from its boiling point, fall from the evaporator into the compressor wand. Pumping from the evaporator, the compressor is pumping refrigerant gas it under high pressure in the condenser. Gaseous refrigerant from condenser cooling, high pressure gradually condenses from a gaseous to a liquid state. Again the liquid refrigerant from the condenser is served by the capillary tube to the evaporator and the cycle repeats.

2. The Chemists is well known for solid carbon dioxide. Carbon dioxide gas is usually transported in steel cylinders, liquefied liquid aggregate phase. When the transmission of gas from the container at room temperature into the gaseous state if his release is intensely, it immediately goes into a solid state, forming a "snow" or "dry ice", with a temperature of sublimation from -79 to $-80{ }^{\circ} \mathrm{C}$. Intense evaporation leads to the solidification of carbon dioxide gas, bypassing the liquid phase. Obviously, the temperature inside the container plus, however, The Chemists is well known for solid carbon dioxide. in this way solid carbon dioxide (dry ice) has a temperature of about $-80{ }^{\circ} \mathrm{C}$ sublime [15].

3. Another important case concerning this topic. Why a person sweats? Everyone knows that under normal circumstances, or when the physical stress, as well as in case of nervous excitement man sweats. Sweat-glands sweat secreted fluid and contains $97.5-99.5 \%$ water, a small amount of salt (chlorides, phosphates, sulfates) and some other substances (organic compounds, urea, uric acid salts, esters of sulfuric acid, creatine) [3]. However, excessive sweating may indicate the presence of serious illnesses. The reasons can be: the common cold, tuberculosis, obesity, impaired cardiovascular system etc. But, importantly, sweating regulates body temperature. Sweating is increased in a hot and humid climate. Usually we sweat when hot. The higher the ambient temperature, the more we sweat. The body temperature of a healthy person is always one of the operating systems and 36.6 methods of maintaining the normal temperature is sweating. Through the pores is intensive evaporation of moisture from the body-person strongly sweats. And the evaporation of moisture from any surface, as indicated above, promotes its cooling. When there is danger for the health the brain causes warning authorities about extradition of sweat to lower body temperature.

4. In addition, the water can also be turned into ice in the glass lab installation (fig. 1), at low pressure without external cooling (at $20^{\circ} \mathrm{C}$ ). You only need to attach to this installation deep vacuum pump with trap.

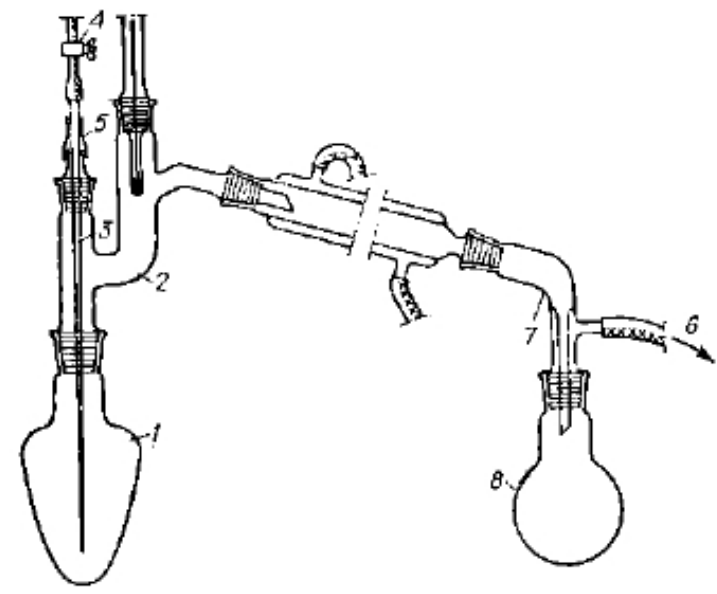

Figure. 1. Laboratory vacuum unit for distillation

In conclusion, I want to address a very important question regarding the layering of hailstones (see Fig. 2-3). What causes turbidity in the structure of hailstones? The authors report that $[5,13,14]$ : "To be hailstone diameter of about 10 centimeters, the ascending air stream in the thundercloud must have a speed not less than $200 \mathrm{~km} / \mathrm{h}$, and thus it includes snowflakes and air bubbles. Such layer looks turbid. But if the temperature is higher, the ice freezes slowly and included snowflakes have time to melt, and the air escapes. Therefore, such a transparent layer of ice". According to these authors, the number of ring inside the hailstones determines how many roamed hailstones up and down. Of Fig. 2-3 clearly shows that the ice that makes up the hailstones, really, are not uniform. Almost every hailstone is pure and in the center of a muddy ice. The opacity of the ice may be caused by various reasons. In large hailstones sometimes alternating layers of transparent and opaque ice. 
In our view, the white layer is responsible for the amorphous and transparent layer is a crystalline form of ice. In addition, the amorphous form of ice aggregate is obtained by extremely rapid cooling of liquid water (at a rate of about $10^{7} \mathrm{~K} / \mathrm{sec}$ ), as well as the rapid increase in the ambient pressure, so that the molecules do not have time to form a crystal lattice [4]. In this case, the lightning creates the favorable conditions for the formation of metastable amorphous ice. From Figure 2-3 shows clearly that the huge boulders were formed from clusters of relatively small hailstones. Both of these factors suggest that the formation of a transparent or opaque layers of hail, caused by exposure to extremely high pressures generated during lightning.

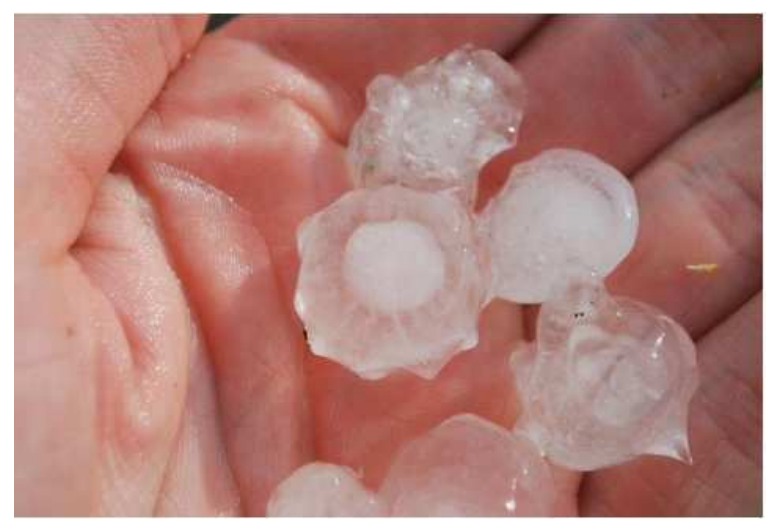

Figure. 2. The amorphous form of ice inside a hailstone

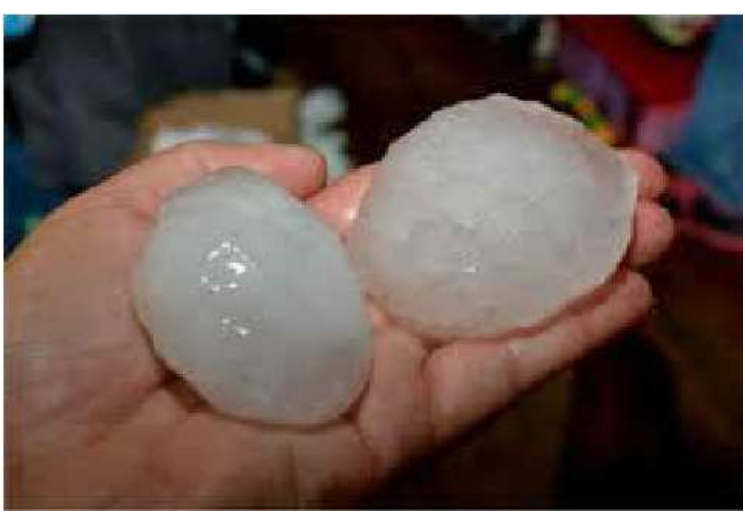

Figure. 3. Aggregation of hailstones

\section{Conclusions}

1. Without the lightning and strong thunderstorms not grad. A thunderstorm accompanied by hail.

2. The cause of hail is instant and massive amounts of heat lightning discharge in the cumulonimbus clouds. The mighty heat produced leads to strong evaporation of water in the channel and around the lightning. Strong water evaporation is rapid cooling ice formation, respectively.

3 . The process does not require the need to shift the zero isotherm atmosphere, with negative temperatures, and can easily occur at low and warm troposphere.

4. The process is essentially close to adiabatic process, since the thermal energy generated is not entered into the system from the outside, and it comes from the system itself.
5. Powerful and intense lightning provides the condition for the formation of large hailstones.

\section{References}

[1] Battal L.J. Person will change the weather. // Gidrometeoizdat. L.: $1965.111 \mathrm{p}$.

[2] Hydrogen properties, production, storage, transportation and application. Under the. Ed. Hamburg, D. Yu, JF Dubovkin M.: Chemistry, 1989. 672 p.

[3] Grashin R.A., Barbinov V.V., Babkin A.V. Comparative evaluation of the effect of liposomal and conventional soaps functional activity apocrine sweat glands and the chemical composition of human sweat // Journal "Dermatology and Cosmetology», 2004. No.1, P. 39.

[4] Russell J. Amorphous ice.-Publ. house «VSD», 2013.157 p.

[5] Ermakov V.I., Stozhkov Y.I. Physics of thunderclouds. LPI RF them. P.N.Lebedev. M.: 2004. 26 p.

[6] Zhelezniak G.V., Kozko A.V. Mysterious phenomena of nature. Proc. club, Kharkiv, 2006. -180 p.

[7] Beginning Ph.M. Physchemistry microcosm. Monograph. T. II. Krasnodar. 2009. 450 p.

[8] Klossowski A. // Works meteor. network NW Russia in 1889, $1890,1891$.

[9] Middleton W. History of the Theories of Rain and other forms of precipitation. L.: Gidrometeoizdat.1969. 198 p.

[10] Millikan R. Electrons (+ and -) protons, photons, neutrons, and cosmic luchi.180 with. English. M-L.: GONTI. 1939. $311 \mathrm{p}$.

[11] Nazarenko A.V. Hazardous weather convective origin. Teaching aid for higher education. Publishing and Printing center of Voronezh State University. 2008. 62 p.

[12] Rusanov A.I. Thermodynamics of nucleation on charged centers. // Dokl. USSR Academy of Sciences, 1978 T. 238. No. 4. P. 831.

[13] Tlisov M.I. Physical characteristics of hail and the mechanisms of its formation. Gidrometeoizdat. 2002. 385 p.

[14] Huchunaev, B.M. Microphysics of origin and prevent hail. Diss. uch. on competition. step. Doctor of Physical and Mathematical Sciences. Nalchik, 2002. 289 p.

[15] George St.Yu. Practical working in organic chemistry. MSU, 1957. No. 2. No. 1. P.39.

[16] Browning K.A., Ludlam F.H. Airflow in convective storms. Quart.// J. Roy. Meteor. Soc. 1962. V.88. P.117.

[17] Buch Ch. L. // Abh. Akad. Berlin. 1814. V.15. S. 74.

[18] Ferrel W. Recent advances in meteorology. Washington: 1886, App. 7L

[19] Gassendi P. // Opera omnia in sex tomos divisa. Leyden. 1658. V. 11. P. 70.

[20] Guyton de Morveau L. B. // Obs. sur la Phys. 1777. Vol. 9. P. 60. 
[21] Ian Strangeways. Precipitation Theory, Measurement and Distribution .// Cambridge University Press. 2006. 290 p.

[22] Mongez J. A. // Obs. sur la Phys. 1778. Vol. 12. P. 202.

[23] Nollet J.A. Recherches sur les causes particulieres des phenomenes electriques. Paris. 1764. P. 324.
[24] Olmsted D. // Amer. J. Sci. 1830. Vol. 18. P. 1.

[25] Volta A. // Metapo sopra la grandine. Giornale de Fisica. Pavia, 1808.Vol.1. pp. 31. 129. 179. 